\title{
INTESTINAL PARASITIC AND BACTERIAL INFECTION AMONG FOOD HANDLERS IN A METROPOLITAN TERTIARY CARE HOSPITAL
}

\author{
Shuvankar Mukhopadhyay ${ }^{1}$, Kirti Malpekar², Jayanthi Shastri ${ }^{3}$ \\ ${ }^{1}$ Senior Registrar, Department of Microbiology, Topiwala National Medical College, Nair Hospital, Mumbai. \\ ${ }^{2}$ Associate Professor, Department of Microbiology, Topiwala National Medical College, Nair Hospital, Mumbai. \\ 3 Professor and HOD, Department of Microbiology, Topiwala National Medical College, Nair Hospital, Mumbai.
}

\section{ABSTRACT}

Food borne diseases are a global public health burden. Food handlers play a major role in the transmission of foodborne diseases. This study was aimed at investigating the presence of intestinal parasites, S. typhi carrier rate and associated risk factors among food handlers in a metropolitan city.

\section{MATERIALS AND METHODS}

A cross-sectional survey was conducted among 200 food handlers working in different food service establishments. A pre-tested structured questionnaire was used to collect data on age, sex, years of service, previous deworming, status of typhoid immunization and hand washing practices. Stool samples were processed for intestinal parasites and S. typhi, as per the standard laboratory methods.

\section{RESULTS}

In the present study, majority of the food handlers were males 185/200 (92.5\%), 90/200 (45\%) were aged between 30-50 years, and $72 / 200(36 \%)$ had less than one year experience. Intestinal parasites were detected in 31/200 (15.5\%) and S. typhi in 2 (1\%). Of the 31 parasites, 11 (35.5\%) were seen by direct saline technique and additional 20 (64.5\%) by formol-ether concentration technique. The parasites found in descending order of frequency among the food handlers were: fertilized eggs of Ascaris lumbricoides 8.5\% (17/200), cyst of Giardia (3.5\%), cyst of Entamoeba histolytica 2\% (4/200), eggs of Taenia spp. 1\% (2/200) and eggs of Trichuris trichiura $0.5 \%$ (1/200). The association of years of work experience was inversely proportional to parasitic infection and directly proportional to history of previous deworming, both of which were statistically significant.

\section{CONCLUSION}

Inexperience and lack of awareness about hygiene in food handlers play a major role in the transmission of food-borne infections. Training on food safety and periodic focused medical check-up can help to control the spread of infection in the community. Laboratory investigation should include formol ether concentration technique to enhance diagnosis.

\section{KEYWORDS}

Intestinal Parasites, Food Handlers, Risk Factors.

HOW TO CITE THIS ARTICLE: Mukhopadhyay S, Malpekar K, Shastri J. Intestinal parasitic and bacterial infection among food handlers in a metropolitan tertiary care hospital. J. Evolution Med. Dent. Sci. 2016;5(62):4327-4331, DOI: $10.14260 /$ jemds/2016/988

\section{INTRODUCTION}

The term "food handler" means "person who in the course of the normal routine work come into contact with uncovered food not intended for personal use." [1] Food handlers play a major role in the transmission of food-borne diseases, which are a major public health problem across the globe. This is particularly true in developing countries due to lack of optimal food handling practices and environmental sanitation. The World Health Organization (WHO) estimated that in developed countries up to $30 \%$ of the population suffer from food-borne diseases each year, whereas in developing countries up to 2 million deaths are estimated per year.[2] Large cities which attract hordes of tourists witness proliferation of eateries ranging from expensive restaurants

Financial or Other, Competing Interest: None.

Submission 12-07-2016, Peer Review 25-07-2016,

Acceptance 27-07-2016, Published 02-08-2016.

Corresponding Author:

Dr. Kirti Malpekar,

404, Audumber So.,

$3^{\text {rd }}$ Akkalkot Lane,

Khadilkar RD,

Girgaon, Mumbai-400004.

E-mail: kirtimalpekar@yahoo.com

DOI: 10.14260/jemds/2016/988 to street food increasing the risk of acquiring various foodborne infections. This study was undertaken to determine the presence of intestinal parasites, Salmonella typhi and associated risk factors among food handlers in a metropolitan city.

\section{MATERIAL AND METHOD}

Laboratory investigation for screening of intestinal parasites is mandatory for employees of eateries across the city as per directives issued by the Public Health Department, for safeguarding the health of the community. This study included 200 food handlers, working in 30 food service establishments from three municipal wards, presenting to a tertiary care hospital from April 2013 to Sep 2013. The data were collected after obtaining approval by the Institutional Ethics Committee and written informed consent from the participants.

\section{Inclusion Criteria}

Normal healthy food handlers (Male and Female).

\section{Exclusion Criteria}

Food handlers suffering from diarrhoeal illness presently or had suffered diarrhoea in last three months and those unwilling to participate in the study. 
A pre-tested structured questionnaire was used to collect data on age, sex, years of service, previous deworming, status of typhoid immunization and hand washing practices. Laboratory investigations included collection of stool specimen in a clean, sterile, screw-capped plastic container and immediate transport to the Microbiology Laboratory of our hospital. Microscopic examination of stool for intestinal parasites was done using both direct mount (Saline/Iodine) and formol ether concentration sedimentation procedures as per the standard procedures (Garcia LS, Diagnostic Medical Parasitology, 5th ed. Washington, DC: ASM Press; 2006). For isolation of Salmonella typhi, stool samples were inoculated in Selenite F broth for 6 hours prior to inoculation on Xylose lysine dextrose agar. After 24 hours of incubation at 37 degrees C, S. typhi was identified following the standard procedures. Participants found positive for intestinal parasites and S. typhi were treated and follow-up stool examination was done. Statistical analysis was done using SPSS version 16.00 software. The Chi-square test was employed to determine the association of intestinal parasites with 'food handlers' hygienic practices, years of experience and previous deworming. A pvalue of $<0.05$ was considered to indicate statistically significant differences.

\section{RESULTS}

Age wise distribution showed that majority 90/200 (45\%) were middle aged, i.e. between 30 to 50 years followed by $77 / 200$ (38.5\%) below 30 years and 33/200 (16.5\%) above 50 years (Table 1); predominantly males 185/200 (92.5\%). According to work experience, majority, i.e. $72 / 200$ (92.5\%) were employed for < 1 year, 70/200 (35\%) for 1-3 years and $58 / 200(29 \%)>3$ years (Table 2). Stool examination with direct mount (saline/iodine) revealed fertilized egg of Ascaris lumbricoides in $11 / 200(5.5 \%)$; there were no mixed infection. Formol ether concentration method, detected parasites in $31 / 200(15.5 \%)$, i.e. in additional 20 cases as compared to direct mount examination. Saline and Iodine mount following concentration of stool by formol ether method revealed parasites in 31/200 (15.5\%) food handlers and 160/200 (84.5\%) showed no parasite. Among the 200 food handlers, $17 / 200(8.5 \%)$ showed fertilised eggs of Ascaris lumbricoides, 7/200 (3.5\%) cyst of Giardia lamblia, $4 / 200(2.0 \%)$ cyst of Entamoeba histolytica, 2/200 (1.0\%) eggs of Taenia spp. and $1 / 200(0.5 \%)$ eggs of Trichuris trichiura (Table 3); there was no mixed infection.

Those (11 food handlers) who were positive for fertilized egg of Ascaris lumbricoides in direct mount were also positive in formol ether concentration method for the same parasite. Infection with Salmonella typhi was seen in $2 / 200$ (1\%). No other bacterial intestinal pathogen was observed. Among the total 31 parasites identified, $11 / 31(35.48 \%)$ parasites were detected by both direct mount and formol ether concentration method and rest 20/31 (64.51\%) by formol ether concentration method only. Considering formol ether concentration as a gold standard, sensitivity of direct mount is $35.48 \%$ but specificity is $100 \%$. Positive predictive value of direct mount is $100 \%$ and negative predictive value is $84.12 \%$
(Table 4). The association between work experience and positive parasite finding showed that 18/72 (25\%) of those employed for less than a year were infected. Parasites were seen in $11 / 70$ (15.7\%) of those with 1-3 years' experience and $2 / 58(3.4 \%)$ with $>3$ yrs. Thus increasing experience was associated with decrease in the rate of parasites infection, which is statistically significant (Pearson chi-square test, df-2, $p$ value 0.003 ). The association between work experience and previous deworming showed that 6/72 (8.3\%) with experience less than 1 year, 22/70 (31.4\%) with experience between 1 and 3 years and 49/58 (84.5\%) with experience $>3$ years were previously dewormed.

The association between years of experience and previous deworming is statistically significant ( $p$-value $<0.0001$ ), years of experience being directly proportional to previous deworming. Thus, the association of increase in years of work experience with both low parasitic infection and history of previous deworming highlights the increase in awareness about food hygiene among experienced workers. Hand hygiene (After touching body parts and any dirty material) was observed in 180/200 (90\%) food handlers, 20/200 (10\%) were unhygienic. Parasite positivity in the hygienic group was $25 / 180(13.8 \%)$ and $6 / 20(30 \%)$ in the unhygienic. Among the infected food handlers, 25/31 (80.6\%) were hygienic and rest $6 / 31(19.4 \%)$ were not. Immunization with typhoid vaccine was noted in 20/200 (10\%) food handlers. All food handlers positive for bacteria and parasite were treated appropriately and follow-up stool examination performed. The follow-up stool examination after treatment were negative.

\begin{tabular}{|c|c|c|}
\hline Age (Years) & No. & Percentage \\
\hline$<30$ & 77 & $38.5 \%$ \\
\hline 30 to 50 & 90 & $45.0 \%$ \\
\hline$>50$ & 33 & $16.5 \%$ \\
\hline Total & $\mathbf{2 0 0}$ & $\mathbf{1 0 0 . 0 \%}$ \\
\hline Table 1: Age Wise Distribution Among the Cases \\
\hline
\end{tabular}

\begin{tabular}{|c|c|c|}
\hline Years of Experience & No. & Percentage \\
\hline$<1$ & 72 & $36.0 \%$ \\
\hline 1 to 3 & 70 & $35.0 \%$ \\
\hline$>3$ & 58 & $29.0 \%$ \\
\hline Total & $\mathbf{2 0 0}$ & $\mathbf{1 0 0 . 0} \%$ \\
\hline Table 2: Distribution According to Years of Experience \\
\hline
\end{tabular}

\begin{tabular}{|c|c|c|}
\hline Formol Ether Concentration & No. & Percentage \\
\hline $\begin{array}{l}\text { Fertilised Egg of Ascaris } \\
\text { lumbricoides }\end{array}$ & 17 & $8.5 \%$ \\
\hline Cyst of Giardia lamblia & 7 & $3.5 \%$ \\
\hline Egg of Taenia Spp. & 2 & $1.0 \%$ \\
\hline Cyst of Entamoeba histolytica & 4 & $2.0 \%$ \\
\hline Egg of Trichuris trichiura & 1 & $0.5 \%$ \\
\hline No OPC & 169 & $84.5 \%$ \\
\hline Total & 200 & $100.0 \%$ \\
\hline \multicolumn{3}{|c|}{$\begin{array}{c}\text { Table 3: Distribution Based on Formol Ether } \\
\text { Concentration Findings }\end{array}$} \\
\hline
\end{tabular}




\begin{tabular}{|c|c|c|c|c|}
\hline \multirow{2}{*}{ Direct Mount } & & \multicolumn{2}{|c|}{ Formol Ether Concentration } & \multirow{2}{*}{ Total } \\
\hline & & Positive & Negative & \\
\hline \multirow[t]{2}{*}{ Positive } & No. & 11 & 0 & 11 \\
\hline & $\%$ & $100.0 \%$ & $0.0 \%$ & $100.0 \%$ \\
\hline \multirow[t]{2}{*}{ Negative } & No. & 20 & 169 & 189 \\
\hline & $\%$ & $10.6 \%$ & $89.4 \%$ & $100.0 \%$ \\
\hline \multirow[t]{2}{*}{ Total } & No. & 31 & 169 & 200 \\
\hline & $\%$ & $15.5 \%$ & $84.5 \%$ & $100.0 \%$ \\
\hline Diagnostic \& Agreement tests & Estimate & Lower 95\% CI & Upper 95\% CI & \\
\hline Sensitivity & $35.48 \%$ & $19.24 \%$ & $54.59 \%$ & \\
\hline Specificity & $100.00 \%$ & $97.84 \%$ & $100.00 \%$ & \\
\hline Predictive value of positive test & $100.00 \%$ & $71.52 \%$ & $100.00 \%$ & \\
\hline Predictive value of negative test & $89.42 \%$ & $84.12 \%$ & $93.41 \%$ & \\
\hline Chi-Square Tests & Value & Df & p-value & Association is- \\
\hline Pearson Chi-Square \$ & 63.458 & 1 & $1.64 \mathrm{E}-15$ & Significant \\
\hline Continuity Correction $\$$ & 56.814 & 1 & $4.79 \mathrm{E}-14$ & Significant \\
\hline Fisher's Exact Test & & & $2.18 \mathrm{E}-10$ & Significant \\
\hline
\end{tabular}

\section{DISCUSSION}

In our study, total 31/200 (15.5\%) food handlers were infected with intestinal parasite (there was no mixed infection). Studies showing higher rate of intestinal parasite infection among food handlers in India and globally were as follows:

\begin{tabular}{|c|c|c|c|}
\hline Author & Rate & Year & Place \\
\hline Prateek et al[3] & $(26.3 \%)$ & 2011 & Mumbai \\
\hline Anant Arunrao et al[4] & $(44.53 \%)$ & 2011 & Solapur \\
\hline Chitnis et al[5] & $(27.9 \%)$ & 1985 & Pune \\
\hline Gupta \& S Kelkar.[6] & $(69.7 \%)$ & 1981 & Nagpur \\
\hline Malhotra et al[7] & $(41.1 \%)$ & 2006 & North India \\
\hline Bayeh Abera et al[8] & $(41.1 \%)$ & 2010 & BahirDarTownNW Ethiopia \\
\hline Gashaw Andargie et al[9] & $(20.1 \%)$ & 2008 & Gondar Town NW Ethiopia \\
\hline M A Babiker et al[10] & $(32.1 \%)$ & 2009 & Khartoum, Sudan \\
\hline Daniel Nigusse et al[11] & $(49.4 \%)$ & 2012 & Accra, Ghana \\
\hline Adnan Al Hindi et al[12] & $(24.3 \%)$ & 2012 & Gaza Strip, Palestine \\
\hline Majed H Wakid et al[13] & $(31.94 \%)$ & 2009 & Makkah \\
\hline Yazici et al[14] & $(29.31 \%)$ & 2007 & Aydin, Turkey \\
\hline Sadek et al[15] & $(19 \%)$ & 1997 & Egypt \\
\hline Teklemariam et al[16] & $(63 \%)$ & 2000 & Hawassa, Ethiopia \\
\hline Idowa \& Rowland et al[17] & $(97 \%)$ & 2006 & Abeokuta, Nigeria \\
\hline Costa et al[18] & $(47.1 \%)$ & 1995 & Uberlandia, Brazil \\
\hline Simsek et al[19] & $(52.5 \%)$ & 2010 & Sanliurfa, SE Anatolia \\
\hline Esparar et al[20] & $(42.4 \%)$ & 2004 & Manila \\
\hline Ayeh Kumi PF et al[21] & $21.6 \%$ & 2009 & Accra, Ghana \\
\hline
\end{tabular}

Studies showing almost similar rate of intestinal parasite infection rate among food handlers compared to present study (15.5\%) were V. Mohan et al[22] 2001 (14\%) (Amritsar), AlLahham AB et al[23] 1990 (18\%) (Irbid, Jordan) and Salem et al[24] 1998 (13.5\%) (Jeddah, Saudi Arabia). Studies showing lower prevalence of intestinal parasite infection in food handlers than our study; (15.5\%) were Khurana et al[25] 2008, (1.3-7\%) North India, Saeed and Hamid et al[26] 2010 (6.9\%) Omduram, Sudan, Gunduz et al[27] 2008 (8.8\%), Manisha, Turkey. Previous study from Mumbai (2010) (Prateek et al) ${ }^{[3]}$ revealed overall parasitic infection rate $26.3 \%$. Reduction of parasite infection among food handlers in our study may be due to improvement of personal hygiene and periodic checkup of food handlers and increase knowledge about hygiene. According to our knowledge, most of the studies from across the world showed higher intestinal parasite infection rate in food handlers compared to Mumbai (15.5\%). High prevalence of intestinal parasite is largely due to poor personal hygiene, lack of environmental sanitation and ignorance of health promotion practices.
In present study, distribution of parasites found in descending order of frequency were fertilized eggs of Ascaris lumbricoides $8.5 \%(17 / 200)$, cyst of Giardia (3.5\%), cyst of Entamoeba histolytica $2 \%(4 / 200)$, eggs of Taenia spp. $1 \%$ (2/200) and eggs of Trichuris trichiura 0.5\% (1/200). There was no evidence of Trematodes, Hookworm and Strongyloides.

Studies showing higher number of Ascaris lumbricoides infection among food handlers compared to our study are V. Mohan et al[22] 2001, Amritsar (28.6\%) Bayeh Abera et al ${ }^{8}$ 2010, Bahir Dar Town, North West Ethiopia (11.7\%) Gashaw Andargie et al[9] 2008, Gondar Town, North West Ethiopia (18.11\%). Studies showing lower number of Ascaris lumbricoides among food handlers compared to our study are Prateek et al[3] 2010, Mumbai (5.1\%) Anant et al[4] 2011, Solapur (6.5\%), Al-Lahham AB et al[23] 1990, Jordan (4.9\%) Ayeh et al[21] 2009, Accra Ghana (5\%), S. Haj Baswaid et al[28] 2008, Yemen (1.7\%) and Majed H. Wakid et al[13] 2009, Makkha $(0.8 \%)$. 
In our study, Salmonella typhi was isolated in $1 \%(2 / 200)$ of food handlers; there was no Shigella infection. The two food handlers infected with Salmonella typhi were most likely asymptomatic carriers, as they did not reveal overt clinical manifestation. Studies showing higher carrier rate of Salmonella infection among food handlers compared to our study were - Khurana et al 2008.[25] North India (1.3\%), AlLahham AB et al[23] 1990 Jordan (6\%), Feglo PK et al[29] 2004 Ghana (2.3\%), Lanata CF et al[30] (5\%), Senthilkumar et al[31] 2005 Namakkal District, Tamilnadu (17.14\%). Studies showing no Salmonella carrier compared to our study were Gashaw et al[9] 2008 Gondar Town, North West Ethiopia; Malhotra et al 2006 North India.[7]; Simsek Z et al 2010 Sanliurfa.[19] Studies showing almost similar carrier rate of Salmonella compared to our study (1\%) were Bayeh et al[8] 2010 Bahir Dar Town, North West Ethiopia (1.85) Mulat Dagnew et al[32] 2013, Gondar University, North West Ethiopia (1.3\%), Misganaw et al[33] 2013, Southern Ethiopia (0.93\%) Gashaw et al[9] 2008 Gondar Town, North West Ethiopia and Lanata CF et al had reported zero percent Shigella infection.[30] among food handlers which was similar to our study. Studies done elsewhere showed prevalence of Salmonellosis among food handlers ranges from 0.032-11\% [Murakami et al[34] 2007, Abera et al ${ }^{8}$ 2010, Saeed and Hamid.[26] 2010, Vaeteewootacharn et al 2008.[35]

In our study parasites were detected in $11 / 200$ (5.5\%) by both direct mount and formol ether concentration technique and 31/200 (15.5\%) parasites were detected by formol ether concentration technique. Therefore, we can see that additional $20 / 200(10 \%)$ food handlers were detected only by formol ether concentration technique, i.e. they were missed by direct examination. If we take formol ether concentration technique as gold standard of parasite infection diagnosis in stool, sensitivity of direct mount is $35.48 \%$ and specificity is $100 \%$. A study from Khartoum, Sudan in 2009 by M.A. Babiker et al has reported that direct mount and formol ether concentration method had detected parasites in $18.6 \%$ and $29.4 \%$ food handlers respectively. ${ }^{[10]}$ Here additional $10.8 \%$ food handlers were detected by formol ether concentration method only, which is similar to our study (10\%). However sensitivity of direct mount compared to formol ether concentration was higher $(63.26 \%)$ than our study (35.48\%). Our study shows that although direct fecal smear is simpler to perform, formol ether concentration technique is far more accurate in providing correct laboratory diagnosis. This requires additional laboratory requirements, such as additional reagents necessitating additional time and effort. These additional requirements will certainly affect the cost of diagnosis by at least 5 times, but individuals or food establishments may be willing to pay the additional cost of more accurate diagnosis. (Esparar et al 2004, Manila).[20]

The association between intestinal parasite infection and years of experience was statistically significant ( $p$ value 0.003 ; Pearson chi square test). Those, who were more experienced ( $>3$ yrs.) were less infected by parasites. The association between years of experience and previous deworming was also statistically significant ( $p$ value $<0.0001$ ); years of experience being directly proportional to positive deworming history. It indicates that previous deworming and awareness, which comes with increased years of work experience may be the cause of low parasite infection rate.
In our study, 20/200 (10\%) food handlers had received typhoid vaccine. One study by Maizun et al, 2002 in Malaysia.[36] has reported higher i.e. 59.6\% typhoid immunisation rate among food handlers, while Prateek et al ${ }^{[3]}$ 2011 from Mumbai has reported lower i.e. 5.1\% typhoid immunisation rate.

Although, no statistically significant association had been found in present study between hand washing (after touching body parts or any dirty material) and parasite infection rate, those who practiced hand washing were less infected (13.8\%) than those who did not $(30 \%)$. This indicates that poor hygiene practice was associated with high rate of intestinal parasitic infection. An Iranian study.[37] showed that reduced hand washing with soap prior to eating after using the toilet or in both situations and contact with soil significantly increased the risk of infection ( $\mathrm{p}=0.0004,0.01,0.0001)$, which was also noted by workers in Solapur.[4] and Mecca, Saudi Arabia. ${ }^{[38]}$ Improper hand washing before handling food is one obvious route for dissemination of infections. Parasite eggs in the soil can be transmitted to vegetables, then on to hands and hence directly into the mouth.[39]

The limitation of our study was the small sample size, due to limited resources and manpower. The educational status and living conditions of food-handlers, which influences personal hygiene was not assessed. Considering the large size of the food sector, more studies need to be performed on a large scale with increased sample size, covering a wide range of food establishments across the city.

\section{CONCLUSION}

Intestinal parasitic infection among food handlers poses a significant health hazard. Good hygiene and safe food-handling should be exercised by food handlers. Strict implementation of periodic medical check-up in addition to proper health education will help to reduce the infection and thereby its spread in the community. To enhance diagnosis, the screening of food handlers should include formol ether concentration technique for stool examination, as it imparts higher yield of parasites compared to direct wet mount. Preventive measures such as typhoid immunisation and regular deworming with appropriate anthelmintics are recommended.

\section{ACKNOWLEDGEMENT}

The authors thank the Public Health Department of MCGM, Ward Officer and Sanitary Inspector for their cooperation and support. We acknowledge all the food handlers for their participation and the Department Technical Staff for assistance.

\section{REFERENCES}

1. Guidelines for the management and health surveillance of food handlers. Department of health directorate: food control. Republic of South Africa, July 2007.

2. WHO food safety and food borne illness, Geneva. WHO 2007.

3. Bhobhate PS, Shrivastava SR, Gupta P. Profile of catering staff at a tertiary care hospital in Mumbai. Australian Med J 2011;4(3):148-54.

4. Takalkar AA, Kumavat AP. Assessment of personal hygiene of canteen workers of government medical college and hospital, Solapur. National J Community Med 2011;2(3):448-51. 
5. Chitnis UK. An evaluation of health status of workers in eating establishments in Pune cantonment. Med J Armed Force Ind 1986;2:34-5.

6. Gupta S, Kelkar YA. Health and hygiene status of food handlers. Indian Medical Gazette 1981;15(8):295-8.

7. Malhotra R, Lal P, Prakash SK, et al. Study of hand hygiene and enteroparasite infestation among food handlers working in a medical college of North India. Indian J Pathol Microbiol 2006;49(2):296-301.

8. Abera B, Biadegelgen F, Bezabih B. Prevalence of salmonella typhi and intestinal parasites among food handlers in Bahir Dar town, Northwest Ethiopia. Ethiop J Health Dev 2010;24(1):46-50.

9. Andargie G, Kassu A, Moges F, et al. Prevalence of bacteria and intestinal parasites among food handlers in Gondar town, Northwest Ethiopia. J Health Popul Nutr 2008;26(4):451-5.

10. Babiker MA, Ali MSM, Ahmed ES. Frequency of intestinal parasites among food handlers in Khartoum, Sudan. Eastern Mediterranean Health J 2009;15(5):1098-104.

11. Nigusse D, Kumie A. Food hygiene practices and prevalence of intestinal parasites among food handlers working in Mekelle university student's cafeteria, Mekelle. Global Advanced Research Journal of Social Science 2012;1(4):065-071.

12. AI-Hindi A, Elmanama AA, Ashour N, et al. Occurrence of intestinal parasites and hygiene characters among food handlers in Gaza Strip, Palestine. Annals of Alquds Medicine 2012;8:2-13.

13. Wakid MH, Azhar EI, Zafar TA. Intestinal parasitic infection among food handlers in the holy city of Makkha during hajj season1428 hegira. JKAU: Med Sci 2009;16(1):39-52.

14. Yazici V, Siriken F, Ertabaklar H, et al. Investigation of intestinal parasites in food workers in hospitals in Aydin, Turkey. Turkiye Parazitol Derg 2007;31(2):136-8.

15. Sadek $\mathrm{Y}$, el-Fakahany $\mathrm{AF}$, Lashin $\mathrm{AH}$, et al. Intestinal parasites among food handlers in Qualyobia governorate, with reference to the pathogenic parasite blastocystis hominis. J Egypt Soc Parasitol 1997;27(2):471-8.

16. Teklemariam S, Roma B, Sorsa S, et al. Assessment of sanitary and hygienic status of catering establishments of Awassa town, Ethiopia. J Health Dev 2000;14(1):91-8.

17. Idowu OA, Rowland SA. Oral fecal parasites and personal hygiene of food handlers in Abeokuta, Nigeria. Afr Health Sci 2006;6(3):160-4.

18. Costa-Cruz JM, Cardoso MLG, Marques DE. Intestinal parasites in school food handlers in the city of Uberlândia, Minas Gerais, Brazil. Rev Inst Med Trop Sao Paulo 1995;37(3):191-6.

19. Simsek Z, Koruk I, Copur AC, et al. Prevalence of staphylococcus aureus and intestinal parasites among food handlers in Sanliurfa, South-Eastern Anatolia. J Public Health Manag Pract 2009;15(6):518-23.

20. Esparar DG, Belizario VY, Relos JRD. Prevalence of Intestinal parasitic infections among food handlers of a tertiary hospital in manila using direct fecal smear and formalin ether concentration technique. Phil J Microbiol Infect Dis 2004;33(3):99-103.

21. Ayeh-Kumi PF, Quarcoo S, Kwakye-Nuako G, et al. Prevalence of intestinal parasitic infections among food vendors in Accra, Ghana. J Trop Med Parasitol 2009;32(1):1-8.
22. Mohan V, Mohan U, Dass L, et al. An evaluation of health status of food handlers of eating establishment in various educational and health institutions in Amritsar city. Ind J Community Med 2001;26(2):80-4.

23. Al-Lahham AB, Abu-Saud M, Shehabi AA. Prevalence of salmonella, shigella and intestinal parasites in food handlers in Irbid, Jordan. J Diarrhoeal Dis Res 1990;8(4):160-2.

24. Salem KA. Infectious diseases among food handlers. J Egypt Public Health Assoc 1998;73(5-6):563-75.

25. Khurana S, Taneja N, Thapar R, et al. Intestinal bacterial and parasitic infections among food handlers in a tertiary care hospital of north India. Trop Gastroenterol 2008;29(4):207-9.

26. Saeed HA, Hamid HH. Bacteriological and parasitological assessment of food handlers in the Omdurman area of Sudan. J Microbiol Immunol Infect 2010;43(1):70-3.

27. Gunduz T, Limoncu ME, Cümen S, et al. The prevalence of intestinal parasites and nasal S. aureus carriage among food handlers. J Environ Health 2008;70(10):64-5, 67.

28. Baswaid SH, AL-Haddad AM. Parasitic infections among restaurant workers in Mukalla (Hadhramaut/Yemen). Iranian J Parasitol 2008;3(3):37-41.

29. Feglo PK, Frimpong EH, Essel-Ahun M. Salmonella carrier status of food vendors in Kumasi, Ghana. East Afr Med J 2004;81(7):358-61.

30. Lanata CF, Tafur C, Benavente $L$, et al. Detection of salmonella typhi carriers in food handlers by viserology in Lima, Peru. Bull Pan Am Health Organ 1990;24(2):177-82.

31. Senthilkumar B, Prabakaran G. Multidrug resistant salmonella typhi in asymptomatic typhoid carriers among food handlers in Namakkal district, Tamil Nadu. Indian J Med Microbiol 2005;23(2):92-4.

32. Dagnew M, Tiruneh M, Moges F, et al. Bacterial profile and antimicrobial susceptibility pattern among food handlers at Gondar university cafeteria, northwest Ethiopia. J Infect Dis Ther 2013;1(2):1-6.

33. Birhaneselassie M, Williams D. A study of salmonella carriage among asymptomatic food handlers in southern Ethiopia. Int J Nutrition and Food Sciences 2013;2(5):2435.

34. Murakami K, Ishihara T, Horikawa $\mathrm{K}$, et al. Features of salmonella serovars among food handlers in Kyushu, Japan. New Microbiol 2007;30(2):155-9.

35. Vaeteewootacharn K, Sutra S, Vaeteewootacharn S, et al. Salmonellosis and the food chain in Khon Kaen, NorthEastern Thailand. Southeast Asian J Trop Med Public Health 2005;36(1):123-9.

36. Zain MM, Naing NN. Sociodemographic characteristics of food handlers and their knowledge, attitude and practice towards food sanitation: a preliminary report. Southeast Asian J Trop Med Public Health 2002;33(2):410-7.

37. Sharif M, Daryani A, Kia E, et al. Prevalence of intestinal parasites among food handlers of Sari, Northern Iran. Rev Inst Med Trop Sao Paulo 2015;57(2):139-44.

38. Zaglool DA, Khodari YA, Othman RAM, et al. Prevalence of intestinal parasites and bacteria among food handlers in a tertiary care hospital. Niger Med J 2011;52(4):266-70.

39. Koyabashi A. Japan international cooperation agency. Textbook for seminar on parasite control administration for senior officers-a step towards primary health care. Tokyo: JICA Ascaris 1999;5:233-42. 